\title{
Grape Berry Vacuole: A Complex and Heterogeneous Membrane System Specialized in the Accumulation of Solutes
}

\author{
Natacha Fontes, ${ }^{1,2}$ Hernâni Gerós, ${ }^{1,2 *}$ and Serge Delrot ${ }^{3}$
}

\begin{abstract}
Vacuoles fulfill highly specialized functions depending on cell type and tissue and plant developmental stage. This complex and dynamic organelle is the main reservoir of grape berry cells, playing a major role during fruit development and ripening. Berry development is accompanied by modifications in size, composition, color, texture, flavor, and pathogen susceptibility, primarily because of changes in vacuolar content. Most aroma and flavor compounds are not evenly distributed in the berry, and the number and type of vacuoles may vary depending on the tissue (skin, flesh, and seeds). Together with the lytic and protein storage vacuoles widely distributed in plant cells, phenolic vacuoles are also implicated in cellular storage in grape cells. After veraison, when grape berry growth exclusively results from cell enlargement, tonoplast transporter proteins mediate a massive sugar import and water intake into the vacuole, leading to a large vacuolar expansion. The V-ATPase and V-PPase pumps create a proton electrochemical gradient across the tonoplast, which, in turn, energizes the uptake of charged and uncharged solutes. Several tonoplast proteins mediating the uptake of sugars, organic acids, water, ions, and anthocyanins have been cloned and some have been functionally characterized. The present review focuses on the storage function of vacuoles and on their structure and diversity in relation to development and ripening of the grape berry.
\end{abstract}

Key words: grape berry, vacuole, tonoplast transporters, sugars, organic acids, phenolics, aroma compounds

Grape (Vitis vinifera L.) is a major crop worldwide. The majority of fruit production is processed into wine, but significant portions are consumed fresh, dried into raisins, processed into nonalcoholic juice, and distilled into spirits (reviewed by Conde et al. 2007). Berry content at harvest is a major parameter for wine quality. Berry size and quality mainly depend on water, sugars (glucose and fructose), organic acids (malic and tartaric acids), phenolic compounds (anthocyanidins and tannins), and aroma precursors.

The vacuoles are an essential organelle for plant cell physiology and therefore for plant life (Martinoia et al. 2007). They are responsible for the high cell surface-to-protoplasmic volume ratio required for extensive exchanges of material and information between plant cells and their environment. The vacuole is surrounded by the tonoplast, a biological membrane that separates the vacuolar lumen from the cytosol. Phospholipids, sterols, and ceramide monohexoside(s) are the

${ }^{1}$ Centro de Investigação e de Tecnologias Agro-Ambientais e Biológicas (CITAB), Quinta de Prados, 5001-801 Vila Real, Portugal; ${ }^{2}$ Departamento de Biologia, Universidade do Minho, Campus de Gualtar, 4710-057 Braga, Portugal; ${ }^{3}$ UMR 1287 Ecophysiology and Grape Functional Genomics, University of Bordeaux, INRA, Institut des Sciences de la Vigne et du Vin, Domaine de la Grande Ferrade, 210 chemin de Leysotte, 33883 Villenave d'Ornon, France. *Corresponding author (email: geros@bio.uminho.pt; tel: + 351253 604048; fax: + 351253 678980)

Acknowledgments: This work was supported in part by the Fundação para a Ciência e a Tecnologia (research project no. PTDC/AGR-ALI/100636/2008; grant no. SFRH/BD/23169/2005 to N.F.).

The authors thank José Soares for the design of Figure 1.

Manuscript submitted Dec 2010, revised Mar 2011, accepted Apr 2011

Copyright $(0) 2011$ by the American Society for Enology and Viticulture. All rights reserved.

doi: 10.5344/ajev.2011.10125 major lipid classes in the tonoplast and plasma membrane, but the content of phospholipids on a protein basis is higher in the tonoplast (Yoshida and Uemura 1986). Together with the cell wall, vacuoles control turgor, which is basic to cell hydraulic stiffness and plant growth (Marty 1999). Recognized functions of the vacuole also encompass storage (ions, metabolites, and proteins), digestion, $\mathrm{pH}$ and ion homeostasis, biotic and abiotic defence responses, toxic compound sequestration, and pigmentation (Marty 1999, Martinoia et al. 2000, Carter et al. 2004). The volume of the grape berry cells is largely occupied by a central vacuole. The vacuole of grape berry cells has attracted attention mainly because its storage function contributes directly to fruit quality. Vacuoles are the main reservoir of grape berry cells for sugars, organic acids, aromas, flavors, ions and water, which are differently distributed throughout berry tissues (Figure 1).

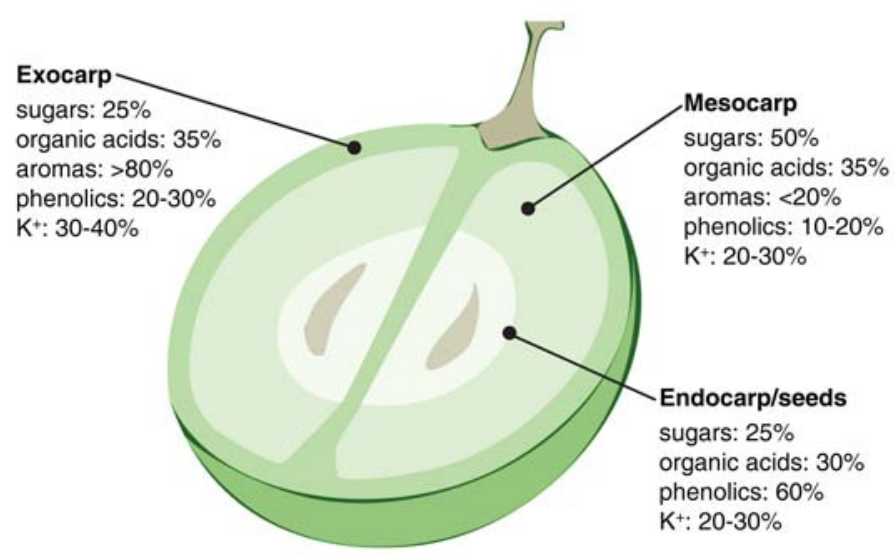

Figure 1 Structure of a ripe grape berry and pattern of solutes distribution (Coombe 1987, Conde et al. 2007, Jackson 2008). Values indicate the percentage of each type of compound in a given compartment, relative to the whole berry. 
Many scientific advances have led to an increased understanding of physiological, biochemical, and molecular aspects of grape berry maturation; however, little is known about the mechanisms, coordination, regulation, and environmental sensitivity of the transport steps involved in vacuolar accumulation of solutes (Shiratake and Martinoia 2007). More generally, despite the importance and uniqueness of fruit vacuoles, the identity and functioning of vacuolar transporters still need further investigation at the molecular level (Maeshima 2001, Shimaoka et al. 2004, Carter et al. 2004, Endler et al. 2006).

The present review focuses on the diversity and biochemistry of the grape berry components, which contribute to the sensory properties of fruit and wine, in relation to their vacuolar compartmentation during berry development and ripening. Emphasis is on the storage function of the vacuoles, which rely on the coordinated activity of transport proteins such as proton pumps and antiporters. Changes in the vacuolation degree and diversity in vacuole morphological will be related to the physiological role of this highly dynamic organelle during fruit development and ripening.

\section{Structure and Biochemical Diversity of Grape Berry Vacuoles}

Plant vacuoles are highly dynamic, multifunctional organelles that provide the primary site of macromolecule storage and turnover. These organelles, which occupy up to $90 \%$ of most mature cells, are an integral part of the endomembrane system, serving as the terminal products of the secretory pathway (Marty 1999). The space-filling function of the vacuole is essential for cell growth, because cell enlargement is accompanied by expansion of the vacuole rather than of the cytosol (Maeshima 2001). Ripe grape berry flesh cells are very heterogeneous, with evident vacuolar diversity in both size (ranging from 1 to $50 \mu \mathrm{m}$ diameter) and content. Vacuoles in these cells vary from large and small colorless vacuoles to numerous small acidic vacuoles distributed throughout the cytoplasm, with a large central vacuole also observable in some cells (Figure 2). The diversity of vacuolar functions

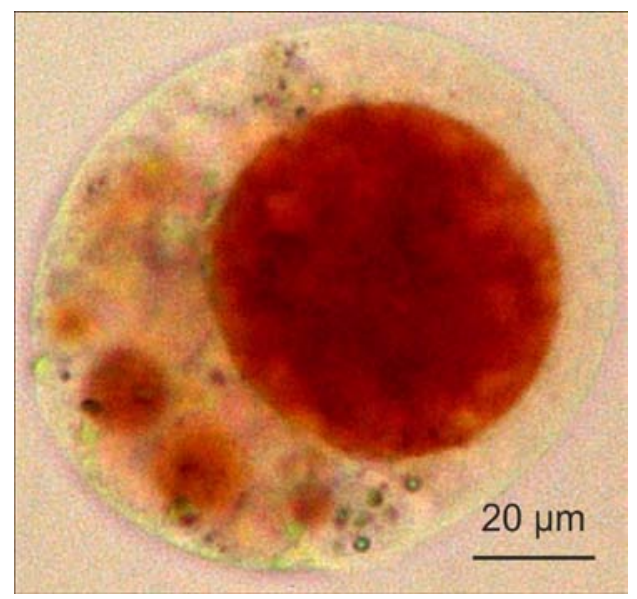

Figure 2 Protoplast from grape berry mesocarp labeled with neutral red to show the acidic nature and integrity of the vacuolar apparatus (adapted from Fontes et al. 2010a). parallels their diversity in morphology, biochemistry, and biogenesis (Marty 1999). As grape berries develop, the vacuolar system displays modifications in vacuole number, size, and composition. As referred to above, fruit volumetric growth after veraison primarily results from vacuolar enlargement by incorporation of water and solute.

The complexity of the vacuolar system offers a rich field of future work for plant biologists. The vacuolar fraction from Arabidopsis thaliana shows the presence of many small vesicles attached to the main vacuole, whose intravesicular environment is also acidic as shown by neutral red staining (Shimaoka et al. 2004). Also, in specialized cells like fleshy cells of the grape berry, the vacuolar volume and content may vary widely (N. Fontes and coworkers, unpublished data, 2011). This diverse vacuolar morphology probably reflects the multiple roles of the vacuole system, as evidenced by many reports that emphasize the existence of different kinds of vacuoles in plants (Paris et al. 1996, Marty 1999, Bethke and Jones 2000). As early as 1876 , from his observations on the anthocyanin vacuoles of Drosera, Charles Darwin documented that in a given tissue, the shape, number, and volume of vacuoles in a cell may vary (De 2000). Indeed, more than one kind of vacuole has been observed in cells undergoing maturation (Bethke and Jones 2000), where some vacuoles primarily function as storage organelles and other as lytic compartments (Paris et al. 1996, Marty 1999, Bethke and Jones 2000, Jiang et al. 2001, Martinoia et al. 2007).

Apart from the lytic vacuoles (LV) and protein storage vacuoles (PSV), widely distributed in plant cells (Paris et al. 1996, Marty 1999, Jauh et al. 1999, Jiang et al. 2001, Reisen et al. 2005), tannin, mucilage, lipid, and phenolic vacuoles have all been described (De 2000). Phenolic vacuoles have been reported as the so-called specialized vacuoles, with distinguishing features that include high phenolic content, avidity for some basic dyes (e.g., neutral red), unusually acidic interior, great sap viscosity, and great refractivity (Minorsky 2001). The avidity of phenolic vacuoles for basic dyes is due to dye precipitation by endogenous phenols. Furthermore, because tannins are, in general, amorphous astringent substances which combine with ferric salts to produce blue, black, or green color in sap, phenolic vacuoles have been named as "A" type, or full cell sap, in contrast to "B" type, or empty cell sap, which do not contain phenolics (De 2000). Secondary metabolites are synthesized, degraded, and stored by a series of integrated processes controlled mainly by membranes and by the different physicochemical conditions present in the different cellular compartments. Because most of these metabolites are toxic to the plant itself, their vacuolar compartmentation may improve the efficiency of their production and avoid harmful effects in the cells (Roytrakul and Verpoorte 2007).

When attempting to study the vacuolar system of grape mesocarp cells, a precise identification mechanism of each compartment is needed. The tonoplast intrinsic proteins (TIPs) are the most abundant vacuolar transporters (reviewed by Gomes et al. 2009), and several TIP genes, typically found in individual plant species, are differentially regulated, suggesting that different TIPs may be utilized under specific 
conditions (Bethke and Jones 2000). Different kinds of vacuoles were shown to be labeled with different combinations of TIPs; thus, TIPs were proposed as markers of vacuole function and developmental stage (Jauh et al. 1999). However, it remains to be confirmed if these antibodies identify TIP orthologs in other species.

The use of fluorescent probes may also be useful in characterizing vacuole functions. However, vacuoles contain large amounts of anthocyanins and flavonols producing an intense autofluorescence, the emission of which varies according to local $\mathrm{pH}$ and ionic conditions, which may impair the utilization of fluorescent probes (Johnson 2006).

Many fine modifications in cell structure, especially those concerning the vacuolation degree and vacuole morphological diversity, may result from environmental constraint and fruit maturation stage. At veraison, the large vacuole splits into smaller vacuoles, generating a complex internal membrane structure. Changes in the vacuolation degree of grape cells may be involved in the maintenance of turgor pressure or in the shift to storage and digestion, as reported for root apex cells of soybean (Klymchuk et al. 2003).

After veraison, the grape berry tissues, and thus the vacuolar content, change from full-scale defence against bird, insect, and fungus to an appealing sugary tissue, with reduced malic acid content. At this time, massive sugar accumulation makes the berry very attractive to birds and mammals and allows seed dispersion (Hardie et al. 1996). Most of the aroma and flavor compounds are not evenly distributed in the berry tissues and their composition and concentration vary along with development and maturation. Accordingly, the vacuolation degree or type of vacuole may also depend on the berry tissue. Prior to ripening, tannins and polyphenols accumulate in outer mesocarp cells that surround the tissues of the peripheral vascular network, and later during ripening they accumulate in greatest abundance in the exocarp cells. In addition to storing tannin compounds, the tannin-rich cells, with tannin vacuoles, may protect the vascular parenchyma cells against UV light. These cells also possess vacuoles acting as intermediate storage sites for the fluxes of assimilates that, as in other tissues, probably exit the phloem of the peripheral vascular network before reentry into the symplast of the pericarp parenchyma (Hardie et al. 1996).

\section{The Vacuole as Storage Compartment}

Major concerns for grapegrowers are the control of ripening time, berry size and color, acidity, and the relative range of volatile and nonvolatile aroma and flavor compounds. Therefore, understanding how and when various components accumulate in the berry and how berry development and maturation responds to environmental stress factors are of critical importance to adjusting grapegrowing practices and thus modifying wine typology (reviewed by Conde et al. 2007).

As stated previously, grape berry vacuoles accumulate sugars, organic acids, aromas, flavors, ions, and water (Figure 1). Each of these compounds is transported across the tonoplast by a specific transporter protein that may be an active pump, a carrier, or a channel. Some tonoplast transporter proteins have been identified and functionally characterized in grape cells (Figure 3), but solute compartmentation in the vacuoles of grapevine cells is still poorly documented.

Two proton pumps energize the vacuolar membrane. Grape berry vacuoles maintain an acidic $\mathrm{pH}$, ranging from $\mathrm{pH} 2.5$ in the green stage to $\mathrm{pH} 3.5$ during ripening. The maintenance of ion and proton concentration gradients across the tonoplast membrane is essential for acid and sugar homeostasis in the berry (Hanana et al. 2007). The low pH of the vacuole of fruit cells is the result of two processes: (1) proton pumping across the tonoplast and (2) synthesis and accumulation of organic acids in the vacuolar sap (Shiratake and Martinoia 2007). Two distinct primary proton pumps, the vacuolar ATPase (V-ATPase) and the vacuolar inorganic pyrophosphatase (V-PPase), generate a proton electromotive force, which, in turn, allows the secondary active transport of inorganic ions, sugars, and organic acids (Blumwald 1987, Maeshima, 2001, Martinoia et al. 2007, Fontes et al. 2010b). The V-PPase is generally more active than the V-ATPase in young tissues with relatively high amounts of pyrophosphate (PPi), which is a by-product of biosynthetic pathways (Martinoia et al. 2007). However, the V-PPase is the predominant vacuolar proton pump in tonoplast vesicles from mature grape berries (Terrier et al. 1998) and intact vacuoles from Cabernet Sauvignon berry suspension cultured cells (Fontes et al. 2010b). Intact vacuoles are good experimental models to monitor the mechanisms of vacuolar acidification and solute uptake (Fontes et al. 2010b).

Vacuolar compartmentation of sugars in grape berry. Although the transport mechanisms of monosaccharides and disaccharides at the plasma membrane level are reasonably understood in several plants, including grapevine, information

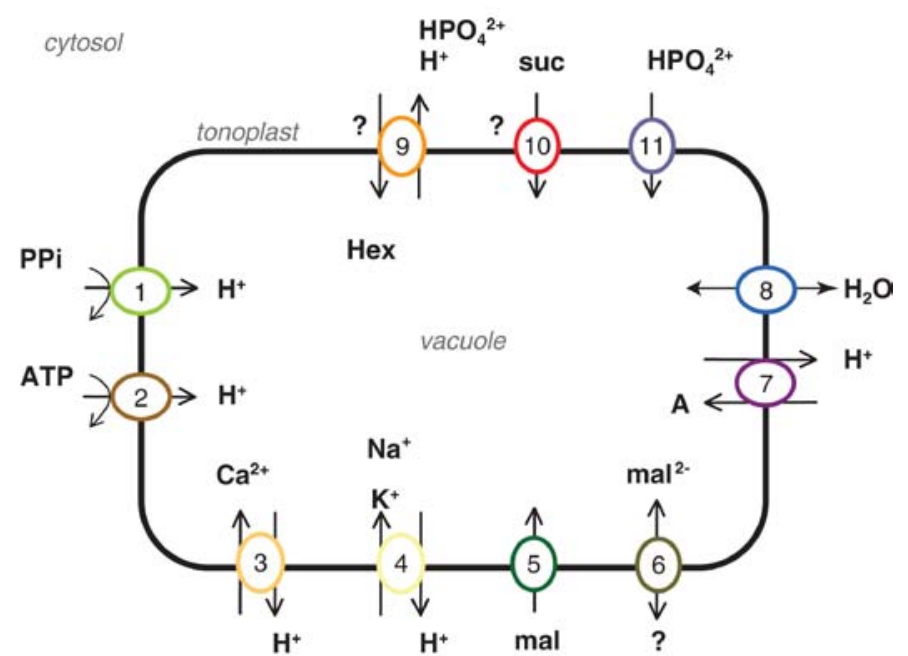

Figure 3 Grape berry vacuolar transport systems identified at molecular level or postulated from transport experiments. (1) V-PPase; (2) VATPase (Terrier et al. 1998, Fontes et al. 2010b); (3) $\mathrm{Ca}^{2+} / \mathrm{H}^{+}$antiport system (Fontes et al. 2010b); (4) cation/ $\mathrm{H}^{+}$antiporter (VvNHX; Hanana et al. 2007); (5) malate (mal) transporter (VvtDT; Rongala 2008); (6) malate channel (VvALMT9; Rongala 2008); (7) MATE transporter implicated in the uptake of acylated anthocyanin (A) (Gomez et al. 2009); (8) tonoplast intrinsic proteins (TIPs; Fouquet et al. 2008); (9) monosaccharide transporter; (10) sucrose (suc) transporters; (11) phosphate transporter (N. Fontes et al. 2011, unpublished data). PPi, pyrophosphate. 
on tonoplast sugar transporters is still limited. However, some tonoplast monosaccharide transporters (TMT) have been recently reported as mediating a proton-coupled antiport mechanism. Three AtTMT (Arabidopsis thaliana tonoplast monosaccharide transporters) isoforms were localized at the tonoplast by fusion with the green fluorescent protein (Neuhaus 2007) and the tonoplast glucose/ $\mathrm{H}^{+}$antiporter AtVGT1 (At3g03090) was characterized in the same plant model (Aluri and Büttner 2007). In $V$. vinifera, the hexose transporter VvHT6 is presumed to be targeted to the tonoplast (reviewed by Agasse et al. 2009). The sequence of VvHT6 is similar to that of the three AtTMT, with an extended loop between the transmembrane helixes six and seven (Büttner 2007, Hayes et al. 2007), and its pattern of expression is consistent with a role in postveraison import of hexoses into the vacuole. Uptake activities of the plasma membrane hexose transporters VvHT1, VvHT4, and VvHT5 have been demonstrated by heterologous expression in the hxt-null mutant yeast, but attempts to confirm the transport activity of VvHT6 has had little success (reviewed by Agasse et al. 2009).

In addition to their role in sugar storage, vacuoles are also involved in the biosynthesis of higher saccharides from monoor disaccharides. Vacuoles are also likely the site for glycosylation and production of various metabolites (De 2000).

Water incorporation in grape berry and the role of aquaporins. Vine water deficit has a clear implication in wine composition and sensory attributes (Roby et al. 2004). It generally leads to smaller berries (Bravdo et al. 1985, Kennedy et al. 2002, Matthews et al. 1990), thus increasing the skin to juice ratio, which, in turn, may increase the concentration of anthocyanins and phenolics in the must and wine (reviewed by Conde et al. 2007).

Most of the berry volume gained before veraison is due to water import through the xylem, whereas most of the postveraison gain is due to water import through the phloem. This strong phloem component at veraison might explain the insensitivity of the berry to plant water deficits (Matthews et al. 1987). In addition, the shift of phloem unloading from symplastic to apoplastic pathway at veraison is associated with sugar accumulation at high levels in sink organs (Patrick 1997, Zhang et al. 2006), favoring the maintenance of a turgor pressure gradient. Moreover, the involvement of cell compartmentation of water and solutes makes it increasingly difficult for the leaves to extract water from ripening berries (Keller et al. 2006). The coexpression of some aquaporins and sugar transporters suggests a functional link between sugar and water fluxes during the processes of unloading and sugar accumulation in the vacuoles of the flesh cells (Delrot et al. 2001). Aquaporins are specialized proteins in the major intrinsic proteins (MIP) family that are implicated in water transport across biological membranes (Fouquet et al. 2008, Gomes et al. 2009).

Eight cDNAs encoding putative Vitis aquaporins (plasma membrane intrinsic proteins, or PIPs, and tonoplast intrinsic proteins, or TIPs) were mostly expressed in roots, eventually enhancing and regulating water permeability (Baiges et al. 2001). The aquaporin VvPIP1A mediates water transport and is mainly expressed in the berries after veraison (Picaud et al. 2003). Moreover, after the release of the grapevine genome in 2007 (Jaillon et al. 2007), 28 genes that encode putative aquaporins were identified and nine cDNAs that encode putative PIP and TIP aquaporins from grape berries at various developmental stages were isolated (Fouquet et al. 2008). Aquaporin gene expression is strongly regulated during berry development and globally decreases during ripening. The tonoplast aquaporin VvTIP2;1 and the plasma membrane aquaporin VvPIP2;1 are highly expressed in dividing and elongating cells and in cells involved in water and solutes transport (Fouquet et al. 2008). More recently, TIP2;1 was confirmed to transport water when individually expressed in Xenopus oocytes (Vandeleur et al. 2009).

Vacuolar compartmentation of malic and tartaric acids. The final organic acid content of grape berry depends on the amount of acid synthesized, stored in the vacuole, and degraded during the ripening stages. Organic acids are produced both in leaves and fruits, but their biosynthetic mechanisms and compartmentation in grape berry cells remain poorly understood. Berry acid content varies throughout berry development and ripening. As reported above, malic acid rapidly accumulates at early stages and decreases at the onset of ripening. Tartaric acid is kept constant and its concentration declines mainly due to dilution as berry volume increases.

During the vegetative growth phase, the sugars from photosynthesis in the leaves are transformed into malic acid, which accumulates in the vacuoles of pericarp cells (Schulze et al. 2002). Also, it is believed that green berries are photosynthetically active and produce malic acid as a source of carbon and energy (Sweetman et al. 2009). Unlike many other fruits, grapes are incapable of storing significant amounts of starch. Malic acid is accumulated in the fleshy cells at the end of the first growth phase of the berry and reaches a maximal value just before veraison. At veraison, due to the severe inhibition of the glycolytic pathway, malic acid import from the large central vacuole allows energy production, lowering grape malate levels. The decrease in malic acid in the grape berry at the onset of ripening also results from reduced malate synthesis, but the reduction in the amount of acid translocated from the leaves to the berries may also play a significant role.

Malate is accumulated in vacuoles at very high concentrations $(>300 \mathrm{mM})$ and the acid exchange across the tonoplast is believed to be driven by the electrochemical membrane potential difference (Martinoia et al. 2007). In Arabidopsis, malate exchange between the vacuole and the cytoplasm is mediated by AttDT, a tonoplast malate transporter (Emmerlich et al. 2003) and by AtALMT9, a tonoplast malate channel (Kovermann et al. 2007). The activity of AttDT is reportedly critical for $\mathrm{pH}$ homeostasis (Hurth et al. 2005).

In grape berry, four good malate transporter candidates have been identified by blast analysis of the $V$. vinifera genome with the AtALMT9 protein sequence (Rongala 2008). These genes are developmentally regulated. VvALMT9:1 and VvALMT9:2 showed postveraison expression, while VvALMT9:3 is expressed at high levels before veraison and VvALMT9:4 is poorly expressed. A single AttDT homologue 
has been identified in $V$. vinifera (Rongala 2008). A homologue of AttDT has been implicated in citrate efflux in citrus fruits (Shimada et al. 2006).

As previously stated, the drop in tartaric acid content, from $150 \mathrm{mM}$ at veraison to 25 to $75 \mathrm{mM}$ at maturity, is mostly due to the increase of the berry size. In addition, the free versus salt state of tartaric acid generally changes throughout maturation, contrary to malic acid, which generally remains as a free acid. Little is known about the biochemical mechanisms involved in tartaric acid accumulation in the vacuole of grape cells.

Vacuolar compartmentation of potassium. Several ions, such as potassium, calcium, magnesium, and chloride, are implicated in numerous physiological processes that impact fruit quality and, ultimately, wine taste and flavor. Therefore, the study of the biochemical steps involved in their compartmentation and interaction with other solutes is of major importance for plant physiologists and viticulturists.

Potassium is an essential macronutrient for grape berry growth and development and a well-known enzyme activator. It is the main cation in must and wine $(\sim 900 \mathrm{mg} / \mathrm{L}$; reviewed by Conde et al. 2007). Potassium is the main osmoticum in skin cells, as sugar is in the flesh. Because potassium may accumulate in the vacuole, it affects several transport processes across the tonoplast membrane. Thus, potassium uptake may increase the release of malic acid, favoring its metabolism in the cytoplasm (Jackson 2008, Davies et al. 2006).

Recently, two cDNAs encoding potassium plasma membrane transporters (VvKUP1 and VvKUP2) from grape berries were isolated and their function was demonstrated by heterologous expression in an Escherichia coli mutant deficient in potassium uptake (Davies et al. 2006). The two transporters are highly expressed in the berry skin during the first phase of berry development, suggesting that, at this time, they play a role either in potassium uptake into the berries or in its compartmentation into the skin cells. However, the transcript levels of both transporters are still significant at postveraison, suggesting that VvKUP1 and VvKUP2 may therefore continue to contribute to potassium homeostasis throughout berry ripening. At the tonoplast level, a NHX-type cation $/ \mathrm{H}^{+}$ antiporter was recently cloned and functionally characterized (Hanana et al. 2007). VvNHX1 couples the passive movement of $\mathrm{H}^{+}$out of the vacuole to the active incorporation of monovalent cations (mainly $\mathrm{K}^{+}$and $\mathrm{Na}^{+}$), playing an important role in vacuolar ion homeostasis in grape berries.

Vacuolar compartmentation of phenolic compounds. Phenolic compounds are an extended family of secondary metabolites in grape berries (Table 1). They are involved in plant protection because they are active growth inhibitors of other living systems. They add color and flavor to the fruit, contributing to the mouthfeel, quality, and palatability of red wines. The major flavors associated with polyphenols are bitterness and astringency. Additionally, they may play important beneficial roles for human health as strong antioxidants (reviewed by Conde et al. 2007) and as activators of the human oestrogen receptor alpha (Chalopin et al. 2010). Many secondary metabolites, particularly phenolic compounds, are frequently accumulated as glycosides, which increases their solubility, transport, and storage ability (De 2000). Nonflavonoid phenolics accumulate primarily in the vacuoles of mesocarp cells, but flavonoids accumulate in the dermal cells of the skin tissue (Table 1).

Tannins or proanthocyanidins are polymers of flavan-3-ols and are the most abundant class of soluble polyphenolics in grape berries. A number of studies involving the identification of several enzymes, transcriptional regulators of proanthocyanidin biosynthesis, and transporters have illustrated the movement of proanthocyanidin precursors into the vacuole (Terrier et al. 2009). Tannins are accumulated in specific vacuoles (tannin vacuoles) and act as deterrents to herbivores

Table 1 Phenolic compounds in the grape berry.

\begin{tabular}{|c|c|c|c|c|c|}
\hline \multirow[b]{2}{*}{ Compound } & \multicolumn{3}{|c|}{ Location $^{\mathrm{a}}$} & \multirow[b]{2}{*}{ Biological role } & \multirow[b]{2}{*}{ Observations (references) } \\
\hline & Skin & Flesh & Seeds & & \\
\hline Flavan-3-ols & +++ & - & + & $\begin{array}{l}\text { Plant defense; flavor: } \\
\text { astringency and bitterness; } \\
\text { color stability (wine) }\end{array}$ & $\begin{array}{l}\text { Larger flavonoid group; catechins (skin and seeds); } \\
\text { gallocatechins (skin); synthesis starts at early stages of } \\
\text { development until veraison (Terrier et al. 2009, Lacopini et al. } \\
\text { 2008) }\end{array}$ \\
\hline Tannins & +++ & + & + & $\begin{array}{l}\text { Flavor: astringency and } \\
\text { bitterness; UV protection }\end{array}$ & $\begin{array}{l}\text { Form cross-links between proteins and other molecules; skin } \\
\text { contains } 89 \% \text { of berry tannins and seeds contain } 11 \% \text {; flesh } \\
\text { contains only soluble tannins at low levels; synthesis and } \\
\text { accumulation starts at early stages of berry development } \\
\text { (Kennedy 2008) }\end{array}$ \\
\hline Anthocyanins & +++ & + & - & $\begin{array}{l}\text { Color; UV protection; } \\
\text { antioxidant activity }\end{array}$ & $\begin{array}{l}\text { Present in skin dermal cells of red varieties; accumulated } \\
\text { as glycosides; malvidin: grape predominant glycoside; flesh } \\
\text { anthocyanins occur in teinturier varieties; anthocyanin vacuolar } \\
\text { inclusions-vacuolar structures of anthocyanin storage; MATE } \\
\text { transporter mediates the incorporation of acylated anthocyanin } \\
\text { (Boss and Davies 2009, Jackson 2008, Conn et al. 2003, 2010, } \\
\text { Gomez et al. 2009) }\end{array}$ \\
\hline Nonflavonoid & - & ++ & +++ & Plant defense & $\begin{array}{l}\text { Includes caftaric and coumaric acids, benzoic and cinnamic } \\
\text { acids; nonflavonoid compounds and tannins are the most } \\
\text { accumulated compounds in grape seeds; synthesis maintained } \\
\text { throughout ripening (Kramling and Singleton 1969, De 2000, } \\
\text { Montealegre et al. 2006) }\end{array}$ \\
\hline
\end{tabular}

aRelative abundance of the compound in each tissue ranges from very abundant (+++) to absent (-). 
and fungi. Beyond astringency, tannins also confer bitterness, which is due to the lowest molecular weight tannins.

The predominant grape berry pigments are the anthocyanins, exclusively produced by red varieties. Carotenoids, xanthophylls, and flavonols, such as quercetin, are also present in both red and white varieties, but they are more important in the color determination of white grapes (Jackson 2008). Pigments are generally confined to the vacuoles of a few cell layers immediately below the epidermis. A few cultivars, called teinturiers, such as Alicante Bouschet, also contain anthocyanins in the mesocarp cells. Whereas flavonoid pigments are deposited in cell vacuoles, carotenoids accumulate predominantly in plastids (Jackson 2008).

Water-soluble anthocyanins are synthesized at the cytosolic surface of the endoplasmic reticulum and further transported to the vacuole, where they are usually sequestered, after being glycosylated (Grotewold 2004). Some enzymes involved in anthocyanin biosynthesis may be tonoplast-bound (Fritsch and Griesbach 1975). Spherical pigmented inclusions are present in the vacuoles of grape cells (Conn et al. 2003, 2010). Sequestration of anthocyanins by anthocyanic vacuolar inclusions, loosely termed "anthocyanoplasts," is believed to increase their stability and to reduce inhibition of certain vacuolar enzymes (Conn et al. 2003, 2010). Anthocyanoplasts start as vesicles in the cytosol and appear membrane-bound (Pecket and Small 1980, Nozzolillo and Ishikura 1988). Once in the vacuole, many factors influence the in vivo pigmentation provided by anthocyanins (Irani and Grotewold 2005). As anthocyanin synthesis and accumulation proceed, the anthocyanin content of the outer hypodermal layer(s) approaches saturation. At this time, anthocyanin combines in self-association or copigment complexes (Jackson 2008). In some cultivars, a decline in anthocyanin content is observed near or after maturity, probably because of $\beta$-glycosidases and peroxidases activity (Jackson 2008).

Anthocyanins assume their distinct color after being transported to the vacuole, and this compartmentation also decreases the feedback inhibition of cytosolic biosynthetic enzymes. The presence and number of hydroxyl groups, methylation, and sugar moiety produce red, violet, and blue coloration. Anthocyanins are red when acidic, colorless at $\mathrm{pH}$ 4.0, and purple above $\mathrm{pH} 4.5$. Under alkaline conditions, a blue color can be produced. The causes of blue color in some cultivars are not known. The blue color of other plant tissues has been attributed to anthocyanin complexes with alkaline metals or to copigmentation in anthocyanin-flavonoid complexes (Mullins et al. 1992).

The expression of the genes involved in anthocyanin biosynthesis is induced by light in seedlings and cell cultures, but the effect of light on the transcriptional activity of the anthocyanin pathway in berry skins is yet to be determined (reviewed by Boss and Davies 2009). Interestingly, light induces an alteration of anthocyanin distribution within vacuolar compartments (Irani and Grotewold 2005). Moreover, the temperature influences anthocyanin accumulation in grape berries, with higher temperatures generally decreasing total anthocyanin levels (Boss and Davies 2009).
While the biosynthesis and regulation of anthocyanins has been extensively described, little is known concerning their sequestration in the vacuole and to what extent their color is affected by storage (Irani and Grotewold 2005). Recently, and due to the sequencing of the grapevine genome (Jaillon et al. 2007), two grapevine proteins belonging to the multidrug and toxic extrusion (MATE) family, anthoMATE1 (AM1) and anthoMATE3 (AM3), have been implicated in the mediated transport of specifically acylated anthocyanin (Gomez et al. 2009). Vacuolar sequestration of anthocyanins is an important process for cell survival because anthocyanins are believed to be toxic (reviewed by Boss and Davies 2009).

Vacuolar compartmentation of aroma compounds. Several hundred volatile compounds have been identified in ripe grapes. Aroma compounds are mostly accumulated in the exocarp (skin) tissue, as previously stated. However, some volatile compounds accumulate differentially between the exocarp and the mesocarp (Luan and Wüst 2002). The final mixture of secondary metabolites in ripe grapes depends on multiple variables, including the grape variety used, the environmental conditions during the growing season, and the management of the vineyard and harvest date (reviewed by Dunlevy et al. 2009). The major groups of aroma and flavor compounds produced in grapes are terpenoids, norisoprenoids (mainly $\mathrm{C}_{13}$-norisoprenoids), aromatics and aliphatics, and also organo-sulfur compounds (with a thiol function) and methoxypyrazines (Table 2).

Most of the literature on grape berry aroma compounds does not specify the vacuole as the main storage compartment for such compounds. Instead, it has been speculated that, after veraison, the plastids that lose their chlorophyll are the site of terpenoid and norisoprenoid synthesis and storage, but in other plants, such as in Pinus species, terpenoid synthesis is carried out by the endoplasmic reticulum (De 2000). Nevertheless, these secondary metabolites are frequently accumulated as glycosides (De 2000, Terrier et al. 2009, Dunlevy et al. 2009), and a number of glycosides also exist in vacuolar sap. In addition to their general storage function, the vacuoles are also involved in the biosynthesis of higher saccharides from mono- or disaccharides and the site of glycosylation and production of various metabolites. Thus, given that glycosylation increases solubility and mobility and facilitates transport and storage processes, the vacuole may act as a reservoir of the glycosylated aroma compounds. Aromas such as terpenes, norisoprenoids, and thiols conjugated with sugars or amino acids are accumulated in the vacuoles of exocarp cells (Lund and Bohlmann 2006). In addition, the $S$-cysteine conjugates have been shown to accumulate in the vacuoles, where the glutathione moiety is cleaved by a peptidase, which yields a specific cysteine conjugate (Peyrot des Gachons et al. 2002).

There have been many advances in understanding how the tonoplast machinery promotes the passage of and accumulates in the vacuole lumen such a variety of compounds, including ions, water, sugars, organic acids, phenolics, aromas, alkaloids, enzyme inhibitors, and toxins, and yet excludes other compounds. This area of research is still in the early stages. 
Table 2 Aroma compounds in the grape berry.

\begin{tabular}{|c|c|c|c|c|c|c|}
\hline \multirow[b]{2}{*}{ Group } & \multirow{2}{*}{$\begin{array}{l}\text { Common } \\
\text { compounds }\end{array}$} & \multicolumn{2}{|c|}{ Location $^{\mathrm{b}}$} & \multirow{2}{*}{$\begin{array}{l}\text { Odor } \\
\text { description }\end{array}$} & \multirow{2}{*}{$\begin{array}{l}\text { Aromatic } \\
\text { precursor } \\
\text { (odorless) }\end{array}$} & \multirow[b]{2}{*}{ Observations (references) } \\
\hline & & Skin & Flesh & & & \\
\hline $\begin{array}{l}\text { Terpenoids } \\
\text { (monoterpenes; } \\
\text { desquiterpenes) }\end{array}$ & $\begin{array}{l}\text { Monoterpenols: } \\
\text { Linalol } \\
\text { Geraniol } \\
\text { Nerol }\end{array}$ & +++ & + & $\begin{array}{l}\text { Rose } \\
\text { Rose } \\
\text { Rose }\end{array}$ & $\begin{array}{l}\text { Glycoside } \\
\text { conjugates }\end{array}$ & $\begin{array}{l}\text { Mostly present in Muscat varieties as both } \\
\text { free (volatile) and bound (nonvolatile) } \\
\text { forms; nerol and geraniol concentrate in } \\
\text { the skin; both free and bound fractions } \\
\text { tend to decline at maturity; synthesized at } \\
\text { endoplasmic retriculum and accumulated } \\
\text { in the vacuoles (Gunata et al. 1985, Park } \\
\text { et al. 1991) }\end{array}$ \\
\hline
\end{tabular}

\begin{tabular}{|c|c|c|c|c|c|}
\hline $\begin{array}{l}\text { Norisoprenoids } \\
\left(\mathrm{C}_{13} \text {-norisoprenoids) }\right.\end{array}$ & $\begin{array}{l}\beta \text {-Damascenone } \\
\beta \text {-Inonone } \\
\text { TDN } \\
\text { Vitispirane }\end{array}$ & + & +++ & $\begin{array}{l}\text { Honey } \\
\text { Violet } \\
\text { Kerosene } \\
\text { Spicy, woody }\end{array}$ & $\begin{array}{l}\text { Glycoside } \\
\text { conjugates }\end{array}$ \\
\hline
\end{tabular}

\begin{tabular}{|c|c|c|c|c|}
\hline $\begin{array}{l}\text { Organo-sulfur } \\
\text { compounds } \\
\text { (thiols) }\end{array}$ & $\begin{array}{l}\text { 3-Sulfanylhexan-1-ol } \\
\\
\text { 2-Methylfuran-3-thiol } \\
\text { 4-Methyl-4-sulfanyl- } \\
\text { pentan-2-one } \\
\text { 3-Sulfanylbutan-1-ol } \\
\text { 3-Sulfanylpentan-1-ol }\end{array}$ & + & + & $\begin{array}{l}\text { Sulfur, passionfruit, cat } \\
\text { urine, boxtree, rhubarb } \\
\text { Meaty } \\
\text { Boxtree } \\
\text { Onion, leek } \\
\text { Grapefruit }\end{array}$ \\
\hline $\begin{array}{l}\text { Methoxypyrazines } \\
\text { (pyrazines) }\end{array}$ & $\begin{array}{l}\text { IPMP } \\
\text { IBMP } \\
\text { SBMP }\end{array}$ & + & - & $\begin{array}{l}\text { Asparagus, green pea, } \\
\text { green pepper } \\
\text { Beet, earthy }\end{array}$ \\
\hline
\end{tabular}

\section{S-Cysteine} conjugates

a dur

Mostly accumulated as bound nonvolatile compounds; only trace amounts of damascenone occurring as free volatile molecules; products of carotenoid degradation; levels increase after veraison; accumulation in the berry not closely related to sugar concentration (Lewinsohn et al. 2005, Razungles et al. 1993)

$S$-cysteine conjugates largely restricted to the skin; suffer further cleavage in the vacuole resulting in a specific cysteine conjugate; precursors appear differently during maturation (Tominaga et al. 1998, Mestres et al. 2000, Francis and Newton 2005)

Positive and negative contribution to wine aroma, flavor, and mouthfeel; vegetative character of Cabernet Sauvignon variety; accumulation peaks before veraison and further drops as berries ripen (Belancic and Agosin 2007, Parr et al. 2007)

aTDN: 1,1,6-trimethyl-1,2-dihydronaphthalene; IPMP: isopropyl methoxypyrazine; IBMP: isobutyl methoxypyrazine; SBMP: sec-butyl methoxypyrazine.

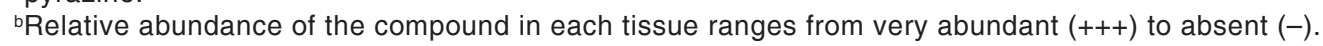

\section{Conclusions and Prospects}

The vacuole is a conspicuous organelle that plays a central role during grape berry development and ripening. Despite the importance and uniqueness of fruit vacuoles, especially grape berry vacuoles, we know little about vacuolar functions and vacuolar transporters. Proteomic methodologies, functional analysis, and molecular characterization of tonoplast transporters should allow significant progress in our understanding of vacuole function. Thus, the isolation and purification of intact vacuoles from grape cells are a prerequisite to understanding the physiology of this organelle. However, the mechanisms that control vacuole identity, as well as those controlling vacuole fusion or division, are poorly known, although some information has been collected in yeasts (Baars et al. 2007). In addition, the topic of how the tonoplast lipid composition-which is certainly changed during grape development and is influenced by environmental factors such as heat-influences vacuole function and solute storage is largely unexplored. The challenge for grape biologists is to deepen the study of vacuole structure, diversity, biochemistry, and dynamics and to integrate this knowledge in the context of cell/tissue type, physiology, and developmental stage.

\section{Literature Cited}

Agasse, A., C. Vignault, C. Kappel, C. Conde, H. Gerós, and S. Delrot. 2009. Sugar transport \& sugar sensing in grape. In Grapevine
Molecular Physiology \& Biotechnology. 2d ed. K.A. RoubelakisAngelakis (ed.), pp. 105-139. Springer Academic, Dordrecht, Netherlands.

Aluri, S., and M. Büttner. 2007. Identification and functional expression of the Arabidopsis thaliana vacuolar glucose transporter 1 and its role in seed germination and flowering. Proc. Natl. Acad. Sci. U.S.A. 104:2537-2542.

Baars, T.L., S. Petri, C. Peters, and A. Mayer. 2007. Role of the VATPase in regulation of the vacuolar fission-fusion equilibrium. Mol. Biol. Cell 18:3873-3882.

Baiges, I., A.R. Schäffner, and A. Mas. 2001. Eight cDNA encoding putative aquaporins in Vitis hybrid Richter-110 and their differential expression. J. Exp. Bot. 52:1949-1951.

Belancic, A., and E. Agosin. 2007. Methoxypyrazines in grapes and wines of Vitis vinifera cv. Carmenere. Am. J. Enol. Vitic. 58:462-469.

Bethke, P.C., and R.L. Jones. 2000. Vacuoles and prevacuolar compartments. Curr. Opin. Plant Biol. 3:469-475.

Blumwald, E. 1987. Tonoplast vesicles for the study of ion transport in plant vacuoles. Physiol. Plant. 69:731-734.

Boss, P.K., and C. Davies. 2009. Molecular biology of anthocyanin accumulation in grape berries. In Grapevine Molecular Physiology \& Biotechnology. 2d ed. K.A. Roubelakis-Angelakis (ed.), pp. 263292. Springer Academic, Dordrecht, Netherlands.

Bravdo, B., Y. Hepner, C. Loinger, S. Cohen, and H. Tabacman. 1985. Effect of irrigation and crop level on growth, yield and wine quality of Cabernet Sauvignon. Am. J. Enol. Vitic. 36:132-139.

Büttner, M. 2007 The monosaccharide transporter(-like) gene family in Arabidopsis. FEBS Lett. 581:2318-2324. 
Carter, C., S. Pan, J. Zouhar, E.L. Ávila, T. Girke, and N. Raikhel. 2004. The vegetative vacuole proteome of Arabidopsis thaliana reveals predicted and unexpected proteins. Plant Cell 16:3285-3303.

Chalopin, M., A. Tesse, M.C. Martinez, D. Rognan, J.F. Arnal, and R. Andriantsitohainan. 2010. Estrogen deceptor alpha as a key target of red wine polyphenols action on the endothelium. PLoSOne 5:e8554.

Conde, C., P. Silva, N. Fontes, A.C.P. Dias, R.M. Tavares, M.J. Sousa, A. Agasse, S. Delrot, and H. Gerós. 2007. Biochemical changes throughout grape berry development and fruit and wine quality. Food (Global Sci. Books) 1:1-22.

Conn, S., C. Franco, and W. Zhang. 2010. Characterization of anthocyanic vacuolar inclusions in Vitis vinifera L. cell suspension cultures. Planta 231(6):1343-1360.

Conn, S., W. Zhang, and C. Franco. 2003. Anthocyanic vacuolar inclusions (AVIs) selectively bind acylated anthocyanins in Vitis vinifera L. (grapevine) suspension culture. Biotechnol. Lett. 25:835-839.

Coombe, B.G. 1987. Distribution of solutes within the developing grape berry in relation to its morphology. Am. J. Enol. Vitic. 38:120-127.

Davies, C., R. Shin, W. Liu, M.R. Thomas, and P. Schachtman. 2006. Transporters expressed during grape berry (Vitis vinifera L.) development are associated with an increase in berry size and berry potassium accumulation. J. Exp. Bot. 57:3209-3216.

De, D.N. 2000. Plant Cell Vacuoles: An Introduction, pp. 38-248. CSIRO, Collingwood, Australia.

Delrot, S., S. Picaud, and J.P. Gaudillère. 2001. Water transport and aquaporins in grapevine. In Molecular Biology \& Biotechnology of the Grapevine. K.A. Roubelakis-Angelakis (ed.), pp. 241-262. Kluwer Academic, Dordrecht, Netherlands.

Dunlevy, J.D., C.M. Kalua, R.A. Keyzers, and P.K. Boss. 2009. The production of flavour and aroma compounds in grape berries. In Grapevine Molecular Physiology \& Biotechnology. 2d ed. K.A. Roubelakis-Angelakis (ed.), pp. 429-460. Springer Academic, Dordrecht, Netherlands.

Emmerlich, V., N. Linka, T. Reinhold, M.A. Hurth, M. Traub, E. Martinoia, and H.E. Neuhaus. 2003. The plant homolog to the human sodium/dicarboxylic cotransporter is the vacuolar malate carrier. Proc. Natl. Acad. Sci. U.S.A. 100:11122-11126.

Endler, A., S. Meyer, S. Schelbert, T. Schneider, W. Weschke, S.W. Peters, F. Keller, S. Baginsky, E. Martinoia, and U.G. Schmidt. 2006. Identification of a vacuolar sucrose transporter in barley and Arabidopsis mesophyll cells by a tonoplast proteomic approach. Plant Physiol. 141:196-207.

Fontes, N., S. Delrot, and H. Gerós. 2010a. A method for the isolation of protoplasts from grape berry mesocarp tissue. Rec. Pat. Biotechnol. 4:125-129.

Fontes, N., R. Silva, C. Vignault, F. Lecourieux, H. Gerós, and S. Delrot. 2010b. Purification and functional characterization of protoplasts and intact vacuoles from grape cells. BMC Res. Notes 3:19.

Fouquet, R., C. Léon, N. Ollat, and F. Barrieu. 2008. Identification of grapevine aquaporins and expression analysis in developing berries. Plant Cell Rep. 27:1541-1550.

Francis, I.L., and J.L. Newton. 2005. Determining wine aroma from compositional data. Aust. J. Grape Wine Res. 11:114-126.

Fritsch, H., and H. Griesbach. 1975. Biosynthesis of cyanidin in cell cultures of Haplopappus gracilis. Phytochemistry 14: 2437-2442.

Gomes, D., A. Agasse, P. Thiébaud, S. Delrot, H. Gerós, and F. Chamount. 2009. Aquaporins are multifunctional water and solute transporters highly divergent in living organisms. Biochim. Biophy. Acta 1788:1213-1228.

Gomez, C., et al. 2009. Grapevine MATE-type proteins act as vacuolar $\mathrm{H}^{+}$-dependent acylated anthocyanin transporters. Plant Physiol. 150:402-415.
Grotewold, E. 2004. The challenges of moving chemicals within and out of cells: Insights into the transport of plant natural products. Planta 219:906-909.

Gunata, Y.Z., C. Bayonove, R. Baumes, and R.E. Cordonnier. 1985. The aroma of grapes, II. The localization and evolution of free and bound fractions of some grape aroma components cv. Muscat during development and maturation. J. Sci. Food Agric. 36:857-862.

Hanana, M., O. Cagnac, T. Yamaguchi, S. Hamdi, A. Ghorbel, and E. Blumwald. 2007. A grape berry (Vitis vinifera L.) cation/proton antiporter is associated with berry ripening. Plant Cell Physiol. 48:804-811.

Hardie, W.J., T.P. O’Brien, and V.G. Jaudzems. 1996. Morphology, anatomy and development of the pericarp after anthesis in grape, Vitis vinifera L. Aust. J. Grape Wine Res. 2:97-142.

Hayes, M.A., C. Davies, and I.B. Dry. 2007. Isolation, functional characterization, and expression analysis of grapevine (Vitis vinifera L.) hexose transporters: Differential roles in sink and source tissues. J. Exp. Bot. 58:1985-1997.

Hurth, M.A., S.J. Suh, T. Kretzschmar, T. Geis, M. Bregante, F. Gambale, E. Martinoia, and H.E. Neuhaus. 2005. Impaired pH homeostasis in Arabidopsis lacking the vacuolar dicarboxylate transporter and analysis of carboxylic acid transport across the tonoplast. Plant Physiol. 137:901-910.

Irani, N.G., and E. Grotewold. 2005. Light-induced morphological alteration in anthocyanin-accumulating vacuoles of maize cells. BMC Plant Biol. 5:7 doi:10.1186/1471-2229-5-7.

Jackson, R.S. 2008. Grapevine structure and function. In Wine Science: Principles and Applications. 3d ed., pp. 50-106. Elsevier, San Diego.

Jaillon, O., et al. 2007. The grapevine genome sequence suggests ancestral hexaploidization in major angiosperm phyla. Nature 449:463-467.

Jauh, G.Y., T.E. Philips, and J.C. Rogers. 1999. Tonoplast intrinsic protein isoforms as markers for vacuolar functions. Plant Cell 11:1867-1882.

Jiang, L., T.E. Phillips, C.A. Hamm, Y.M. Drozdowicz, P.A. Rea, M. Maeshima, S.W. Rogers, and J.C. Rogers. 2001. The protein storage vacuole: A unique compound organelle. J. Cell Biol. 155:991-1002.

Johnson, I.D. 2006. Practical considerations in the selection and application of fluorescent probes In Handbook of Biological Confocal Microscopy. 3d ed. J.B. Pawley (ed.), pp. 353-367. Springer Science, New York.

Keller, M., J.P. Smith, and B.R. Bondada. 2006. Ripening grape berries remain hydraulically connected to the shoot. J. Exp. Bot. 57:2577-2587.

Kennedy, J.A. 2008. Grape and wine phenolics: Observations and recent findings. Cien. Inv. Agr. 35:107-120.

Kennedy, J.A., M.A. Matthews, and A.L. Waterhouse. 2002. Effect of maturity and vine water status on grape skin and wine flavonoids. Am. J. Enol. Vitic. 53:268-274.

Klymchuk, D.O., E.L. Kordyum, T.V. Vorobyova, D.K. Chapman, and C.S. Brown. 2003. Changes in vacuolation in the root apex cells of soybean seedlings in microgravity. Adv. Space Res. 31:2283-2288.

Kovermann, P., S. Meyers, S. Hortensteiner, C. Picco, J. ScholzStarke, S. Ravera, Y. Lee, and E. Martinoia. 2007. The Arabidopsis vacuolar malate channel is a member of the ALMT family. Plant J. 52:1169-1180

Kramling, T.E., and V.L. Singleton. 1969. An estimate of the nonflavonoid phenols in wines. Am. J. Enol. Vitic. 20:86-92.

Lacopini, P., M. Baldi, P. Storchi, and L. Sebastiani. 2008. Catechin, epicatechin, quercetin, rutin and resveratrol in red grape: Content, in vitro antioxidant activity and interactions. J. Food Compos. Anal. 21:589-598.

Lewinsohn, E., Y. Sitrit, E. Bar, Y. Azulay, M. Ibdah, A. Meir, E. Yosef, D. Amir, and Y. Tadmor. 2005. Not just colors-Carotenoid 
degradation as a link between pigmentation and aroma in tomato and watermelon fruit. Trends Food Sci. Technol. 16:407-415.

Luan, F., and M. Wüst. 2002. Differential incorporation of 1-deoxyD-xylulose into (3S)-linalool and geraniol in grape berry exocarp and mesocarp. Phytochemistry 60:451-459.

Lund, S.T., and J. Bohlmann. 2006. The molecular basis for wine grape quality-A volatile subject. Science 311:804-805.

Maeshima, M. 2001. Tonoplast transporters: Organization and function. Ann. Rev. Plant Physiol. Plant Mol. Biol. 52:469-497.

Martinoia, E., M. Maeshima, and H.E. Neuhaus. 2007. Vacuolar transporters and their essential role in plant metabolism. J. Exp. Bot. 58:83-102.

Martinoia, E., A. Massonneau, and N. Fragne. 2000. Transport processes of solutes across the vacuolar membrane of higher plants. Plant Cell Physiol. 41:1175-1186.

Marty, F. 1999. Plant vacuoles. Plant Cell. 11:587-599.

Matthews, M.A., M.M. Anderson, and H.R. Schultz. 1987. Phenologic and growth responses to early and late season water deficits in Cabernet franc. Vitis 26:147-160.

Matthews, M.A., R. Ishii, M.M. Anderson, and M. O’Mahony. 1990. Dependence of wine sensory attributes on wine water status. J. Sci. Food Agric. 51:321-335.

Mestres, M., O. Busto, and J. Guasch. 2000. Analysis of organic sulphur compounds in wine aroma. J. Chromatogr., A 881:569-581.

Minorsky, P.V. 2001. News from the archives. Plant Physiol. 127:15701571.

Montealegre, R.R., R.R. Peces, J.L.C. Vozmediano, J.M. Gascueña, and E.G. Romero. 2006. Phenolic compounds in skins and seeds of ten grape Vitis vinifera varieties grown in a warm climate. J. Food Comp. Anal. 19(6-7):687-693.

Mullins, M.G., A. Bouquet, and L.E. Williams. 1992. Developmental physiology: Flowering and fruiting. In Biology of the Grapevine, pp. 80-111. Cambridge University Press, UK.

Neuhaus, H.E. 2007. Transport of primary metabolites across the plant vacuolar membrane. FEBS Lett. 581:2223-2226.

Nozzolillo, C., and N. Ishikura. 1988. An investigation of the intracellular site of anthocyanoblasts using isolated protoplasts and vacuoles. Plant Cell Rep. 7:389-392.

Paris, N., C.M. Stanley, R.L. Jones, and J.C. Rogers. 1996. Plant cells contain two functionally distinct vacuolar compartments. Cell 85:563-572.

Park, S.K., J.C. Morrison, D.O. Adams, and A.C. Noble. 1991. Distribution of free and glycosidically bound monoterpenes in the skin and mesocarp of Muscat of Alexandria grapes during development. J. Agric. Food Chem. 39:514-518.

Parr, W.V., J.A. Green, K.G. White, and R.R. Sherlock. 2007. The distinctive flavour of New Zealand Sauvignon blanc: Sensory characterization by wine professionals. Food Qual. Pref. 18:849-861.

Patrick, J.W. 1997. Phloem unloading: Sieve element unloading and post-sieve element transport. Ann. Rev. Plant Physiol. Plant Mol. Biol. 48:191-222.

Pecket, C.R., and C.J. Small. 1980. Occurrence, location and development of anthocyanoplasts. Phytochemistry 19:2571-2576.

Peyrot des Gachons, C., T. Tominaga, and D. Dubourdieu. 2002. Sulfur aroma precursor present in $S$-glutathione conjugate form: Identification of $S$-3-(hexan-1-ol)-glutathione in must from Vitis vinifera L. cv. Sauvignon blanc. J. Agric. Food Chem. 50:4076-4079.
Picaud, S., F. Becq, F. Dédaldéchamp, A. Ageorges, and S. Delrot. 2003. Cloning and expression of two plasma membrane aquaporins expressed during the ripening of grape berry. Funct. Plant Biol. 30:621-630.

Razungles, A., Z. Gunata, S. Pinatel, R. Baumes, and C. Bayonove. 1993. Quantitative studies on terpenes, norisoprenoids and their precursors in several varieties of grapes. Sci. Alim. 13:59-72.

Reisen, D., F. Marty, and N. Leborgne-Castel. 2005. New insights into the tonoplast architecture of plant vacuoles and vacuolar dynamics during osmotic stress. BMC Plant Biol. 5:1-13.

Roby, G., J.F. Harbertson, D.A. Adams, and M.A. Matthews. 2004. Berry size and vine water deficits as factors in winegrape composition: Anthocyanins and tannins. Aust. J. Grape Wine Res. 10:100-107.

Rongala, J. 2008. Identification and localization of vacuolar organic acid carriers in grapevine berries. Thesis, University of Adelaide, School of Agriculture, Food and Wine, Waite Campus.

Roytrakul, S., and R. Verpoorte. 2007. Role of vacuolar transport proteins in plant secondary metabolism: Catharanthus roseus cell culture. Phytochem. Rev. 6:383-396.

Schulze, J., M. Tesfaye, R.H.M.G. Litjens, B. Bucciarelli, G. Trepp, S. Miller, D. Samac, D. Allan, and C.P. Vance. 2002. Malate plays a central role in plant nutrition. Plant Soil 247:133-139.

Shimaoka, T., M. Ohnishi, T. Sazuka, N. Mitsuhashi, I. Hara-Nishimura, K.I. Shimazaki, M. Maeshima, A. Yokota, R.I. Tomizawa, and T. Mimura. 2004. Isolation of intact vacuoles and proteomic analysis of tonoplast from suspension-cultured cells of Arabidopsis thaliana. Plant Cell Physiol. 45:672-683.

Shimada, T., R. Nakano, V. Shulaev, A. Sadka, and E. Blumwald. 2006. Vacuolar citrate $/ \mathrm{H}^{+}$symporter of citrus juice cells. Planta 224:472-480.

Shiratake, K., and E. Martinoia. 2007. Transporters in fruit vacuoles. Plant Biotech. 24:127-133.

Sweetman, C., L.G. Deluc, G.R. Cramer, C.M. Ford, and K.L. Soole. 2009. Regulation of malate metabolism in grape berry and other developing fruits. Phytochemistry 70:1329-1344.

Terrier, N., C. Deguilloux, F.X. Sauvage, E. Martinoia, and C. Romieu. 1998. Proton pumps and anion transport in Vitis vinifera: The inorganic pyrophosphatase plays a predominant role in the energization of the tonoplast. Plant Physiol. Biochem. 36:367-377.

Terrier, N., D. Ollé, C. Verriès, and V. Cheynier. 2009. Biochemical and molecular aspects of flavan-3-ol synthesis during berry development. In Grapevine Molecular Physiology \& Biotechnology. 2d ed. K.A. Roubelakis-Angelakis (ed.), pp. 429-460. Springer Academic, Dordrecht, Netherlands.

Tominaga, T., C. Peyrot des Gachons, and D. Dubourdieu. 1998. A new type of flavor precursors in Vitis vinifera L. cv. Sauvignon blanc: S-cysteine conjugates. J. Agric. Food Chem. 46:5215-5219.

Vandeleur, R.K., G. Mayo, M.C. Shelden, M. Gilliham, B.N. Kaiser, and S.D. Tyerman. 2009. The role of plasma membrane intrinsic protein aquaporins in water transport through roots: Diurnal and drought stress responses reveal different strategies between isohydric and anisohydric cultivars of grapevine. Plant Physiol. 149:445-460.

Yoshida, S., and M. Uemura. 1986. Lipid composition of plasma membranes and tonoplasts isolated from etiolated seedlings of mung bean (Vigna radiata L.). Plant Physiol. 82:807-812

Zhang, X.Y., X.L. Wang, X.F. Wang, G.H. Xia, Q.H. Pan, R.C. Fan, F.Q. Wu, X.C. Yu, and D.P. Zhang. 2006. A shift of phloem unloading from symplasmic to apoplasmic pathway is involved in developmental onset of ripening in grape berry. Plant Physiol. 142:220-232. 